\title{
La negación metadiscursiva: una mirada psicoanalítica
}

\author{
The metadiscursive negation: a psychoanalytic look \\ A negação metadiscursiva: uma olhada psicanalítica \\ Marcela Cazes \\ Universidad de Buenos Aires - Buenos Aires - Argentina
}

$\diamond$

\begin{abstract}
Resumen: El presente artículo se propone analizar el discurso de un integrante del staff directivo de una Organización no Gubernamental (ONG) formada por jóvenes voluntarios universitarios que trabaja en la construcción de viviendas mínimas en distintos barrios carenciados de Latinoamérica. La característica distintiva de su discurso es la de definirse en oposición al 'asistencialismo', al que identifica con el modo de gestión del Estado, contraponiendo la cultura del esfuerzo y el compromiso como marcos discursivos adecuados para describir la gestión de los integrantes de la ONG en relación a los beneficiarios. El análisis discursivo se enfoca en el uso de enunciados estructurados en base a la negación metadiscursiva en fragmentos de discurso oral. Se plantea que esta estrategia argumentativa podría responder al mecanismo psíquico de la denegación que, como instancia simbólica, se instalaría con el fin de lograr una salida posible al entramado imaginario de la identificación especular.
\end{abstract}

Palabras clave: argumentación; oposición; identificación; negación

Resumo: O presente artículo se propõe analisar o discurso de um integrante do staff diretivo de uma Organização nao Governamental (ONG) formada por jovens voluntários universitários que trabalha na construção de vivendas mínimas em diferentes bairros desprovidos de Latino América. A característica distintiva de suo discurso é a de definir-se em oposição ao "assistencialismo", ao que identifica com o modo de gestão do Estado, contrapondo a cultura do esforço e o compromisso como marcos discursivos apropriados para descrever a gestão dos integrantes da ONG em relação aos beneficiários. A análise discursiva é focalizada no uso de enunciados estruturados com base na negação metadiscursiva em fragmentos de discurso oral.Pensa-se que esta estratégia argumentativa poderia responder ao mecanismo psíquico da denegação, que como instância simbólica, se instalaria com o fim de alcançar uma saída possível à rede imaginaria da identificação especular.

Palavras-chave: Argumentação; oposição; identificação; negação

Abstract: The present article proposes to analyze the discourse of a member of the directive staff of a Non-Governmental Organization (NGO) constituted by university volunteer younger students that works in the construction of minim housings in different lacking neighborhoods of Latin America. The distinctive characteristic of his discourse is to define it in opposition to "welfarism", which he identifies with the State way of management, countering the effort and commitment culture like adequate discursive frames to describe the NGO members' management in relation to the beneficiaries. The discursive analysis focuses in the use of structured announcementson the basis of the metadiscursive negation in verbal discourse fragments. It sets out that this argumentative strategy could answer to the refusal psychic mechanism that, like symbolic instance, would be installed with the finality to obtain a possible issue fromthe imaginary scheme of the mirrored identification.

Keywords: Argumentation; opposition; identification; negation 


\section{Introducción}

Este artículo se inscribe en el marco del Proyecto UBACyT "Movimientos sociales que resisten la exclusión: alternativas y dificultades en procesos de participación y transformación ciudadanas"1. Como parte de un plan más amplio, la presente comunicación aporta a uno de los objetivos generales de la investigación que consiste en explorar y describir los niveles de modelamiento y padecimiento subjetivos que tienen lugar en ámbitos caracterizados por la horizontalidad y la cooperación en contextos de asimetría extrema. De modo más específico, este trabajo analiza el discurso de un miembro del staff directivo de una Organización no Gubernamental $(\mathrm{ONG})^{2}$ formada por jóvenes voluntarios que trabaja en la construcción de viviendas mínimas en distintos barrios carenciados de Latinoamérica. En tal sentido, el corpus que se analiza está conformado por una serie de fragmentos de discurso oral extraídos de una entrevista realizada al referido integrante de la ONG en el marco de esta investigación.

A partir de la transcripción textual del material grabado, ha llamado la atención las particularidades argumentativas sobre las que el entrevistado organiza su discurso: el recurrente empleo de enunciados estructurados en base a la negación metadiscursiva (GARCÍA NEGRONI, 2009-2013). Por tal motivo, el objetivo de este trabajo es analizar el uso de enunciados del tipo -no p, sino q-en fragmentos de discurso oral. En esta línea, la pregunta que dirigirá la siguiente indagación es: ¿a qué responde el uso frecuente de la negación metadiscursiva en el marco de un relato oral?

Dado que la presente comunicación es apenas un esbozo exploratorio que formará parte de una investigación más amplia, no se planteará en esta oportunidad una hipótesis formal, sino una suerte de hipótesis de trabajo o ideas previas que expliciten los supuestos iniciales. En esta línea se plantea que el hablante necesita afirmarse en su propio universo discursivo a partir de refutar, en primera instancia, otros campos discursivos posibles. De esta manera, apoya su argumentación en una estrategia de oposición, creando un espacio de máxima diferenciación con su virtual oponente. Esta estrategia discursiva podría responder al mecanismo psicológico de la denegación que, como instancia simbólica, se instalaría con el fin de

\footnotetext{
1 Programación Científica UBACyT 2014-2017. Sede: Instituto de Investigaciones de la Facultad de Psicología de la Universidad de Buenos Aires. Directora Dra. Margarita Robertazzi.

2 Acorde con el criterio ético de preservar la identidad de la persona entrevistada, se omitirá en esta oportunidad el nombre de la ONG aludida, así como las referencias de la página web, considerando que esta omisión no resultará perjudicial para la presentación y el análisis de los enunciados.

3 Se conserva aquí el criterio ético planteado en la nota 2, por lo que se omiten las referencias a la página web mencionada.
}

lograr una salida posible al entramado imaginario de la identificación especular.

El enfoque teórico que se propone para abordar el análisis enunciativo del discurso es el de la Semántica Argumentativa, compuesta por la Teoría Polifónica de la Enunciación -formulada por Oswald Ducrot, en 1984-y la Teoría de la Argumentación en la Lengua, en su versión estándar; esto es, en su articulación con la Teoría de los Topoi -elaborada por Jean Claude Anscombre y Oswald Ducrot, en 1986-. Asimismo, se considerarán los aportes de la Teoría Psicoanalítica acerca del concepto de la Identificación y el mecanismo psíquico de la Denegación.

\section{Algunas consideraciones acerca del corpus}

Se trata de una ONG latinoamericana formada por jóvenes voluntarios. Fundada en Chile en 1997 por un grupo de estudiantes universitarios liderados por un capellán, actualmente se encuentra presente en una decena de países del continente, entre ellos, Argentina.

Con el fin de contextualizar el análisis de los enunciados, se presentan a continuación algunos fragmentos extraídos de la página $w^{2} b^{3}$ de la organización en cuestión:

A través de un modelo de intervención propio, trabajamos con quienes viven en la extrema pobreza para que logren desarrollarse como comunidad, sin recurrir al asistencialismo, y mediante el esfuerzo conjunto de voluntarios y familias beneficiadas.

Trabajamos en la construcción de viviendas mínimas, estas dan solución rápida y concreta a las familias que viven en situación de emergencia brindándoles un lugar íntimo, digno y protegido para desarrollarse.

Es una casa fácil de construir y muy económica, lo que posibilita estar al alcance de las familias con menores recursos y la participación de jóvenes voluntarios en la construcción. (...) es un módulo de madera de 18 metros cuadrados (6mts. X $3 \mathrm{mts}$ ) formado por dos paneles de piso, seis paneles laterales, una puerta, dos ventanas, vigas de madera y techo de chapa zinc; a su vez la vivienda se encuentra sobre 17 pilotes que la aíslan y protegen de la humedad.

\section{La Teoría Polifónica de la Enunciación}

En el marco de la pragmática semántica o pragmática lingüistica, tal como el mismo Oswald Ducrot (1984) nombra a la disciplina en la que se inscriben sus estudios, el autor se propone -como principal objetivoimpugnar y reemplazar el postulado de la unicidad del sujeto hablante, que sostenía la lingüística moderna, a través de la Teoría Polifónica de la Enunciación (en 
adelante, TPE). En tal sentido, el problema propiamente lingüístico, y que precisamente forma parte de lo que el autor denomina pragmática lingüistica, atañe a que ya no se trata de lo que se hace al hablar, sino de lo que el habla -según el enunciado mismo- supuestamente hace. Entonces, para Ducrot (1984, p. 178), el punto reside en que esa incitación a actuar o esa obligación de responder se dan como efecto de la enunciación. Así, el objeto de la pragmática semántica o lingüística es dar cuenta de aquello que, según el enunciado, el habla hace. Para alcanzar este objeto, el autor propone describir sistemáticamente las imágenes de la enunciación que son vehiculizadas por el enunciado. En esta línea de pensamiento, la concepción del sentido con la que trabaja Ducrot (1984, p. 187) no es una hipótesis susceptible de ser verificada o falsificada, sino que equivale a considerar el sentido como una descripción de la enunciación. Así, lo que el sujeto hablante comunica por medio de su enunciado es una cualificación de la enunciación de ese enunciado; es decir, el sentido del enunciado es una representación de la enunciación. En otras palabras, el enunciado aporta indicaciones en relación con las fuentes de la enunciación (indicaciones contenidas en el sentido del enunciado), por lo que el objeto propio de una concepción polifónica del sentido es mostrar cómo el enunciado señala -en su enunciación- la superposición de varias voces:

Cierto que cuando definí la noción de enunciación, tal como la utilizo en cuanto lingüista que describe el lenguaje, me negué explícitamente a introducir en ella la idea de un productor del habla: mi noción es neutra con relación a una idea semejante. Pero otra cosa ocurre con esa descripción de la enunciación que es constitutiva del sentido de los enunciados, aquella que es constitutiva de lo que el enunciado quiere decir y no ya de lo que el lingüista dice de él. Ella entraña, o puede entrañar, la atribución a la enunciación de uno o varios sujetos que serían su origen (DUCROT, 1994, p. 197).

En efecto, y tal como lo plantean García Negroni y Tordesillas (2001, p. 174), con la noción de polifonía, Ducrot formula que el autor de un enunciado no se expresa directamente, sino que pone en escena -en el enunciado mismo- un cierto número de personajes, de figuras discursivas. Así, el sentido del enunciado nace de la confrontación de los diferentes personajes, siendo el resultado de diferentes voces que allí aparecen. Con esta concepción se rompe -como ya ha sido anticipado-con el axioma de la unicidad del sujeto hablante, que postula que detrás de cada enunciado habría una y solamente una persona que habla. Por el contrario, para la TPE, en un mismo enunciado están presentes varios personajes con estatutos lingüísticos y funciones diferentes; es decir, diferentes figuras discursivas que el propio sentido del enunciado genera. En esta línea de pensamiento, Ducrot (1984) propone tres figuras esenciales vinculadas con el sujeto hablante: el sujeto empírico, el locutor y el enunciador.

En cuanto al locutor (L), podría caracterizarse como una ficción discursiva que no coincide necesariamente con el sujeto empírico (SE) -el autor efectivo o productor del enunciado- $\mathrm{y}$ hasta puede ser totalmente diferente. Tal como lo plantea Ducrot (1984, p. 198), el L es un ser que, en el sentido mismo del enunciado, es presentado como su responsable, es decir como alguien a quien se debe imputar la responsabilidad de ese enunciado. A él remiten el pronombre yo y las otras marcas de la primera persona. Pero, como ya ha sido dicho, el L, designado por yo, puede ser distinto del SE; y ello aun si los dos personajes coinciden habitualmente en el discurso oral.

Por otra parte, Ducrot (1984, p. 204) distingue también, en el interior de la noción de locutor, entre el locutor como tal (L) y el locutor como ser del mundo $(\lambda)$. Así, L es el responsable de la enunciación, considerado únicamente en virtud de esa propiedad; en tanto $\lambda$ es una persona "completa" que, entre otras propiedades, posee la de ser origen del enunciado. Ahora bien, tanto L como $\lambda$ son seres de discurso, constituidos en el sentido del enunciado; así, los rasgos atribuidos al locutor -por su enunciación misma- provienen de L, pero si L habla de sí mismo como ser del mundo, será entonces $\lambda$ quien estará implicado.

Por último, la noción de enunciador (E) permite a Ducrot $(1984$, p. 208) presentar la forma más frecuente de la polifonía, al proponer que todo enunciado presenta cierto número de puntos de vista relativos a las situaciones de las que se habla. Llama enunciadores a esos seres que supuestamente se expresan a través de la enunciación, sin que por ello se les atribuyan palabras precisas:

(...) si ellos 'hablan', es solo en el sentido de que la enunciación aparece como si expresara su punto de vista, su posición, su actitud, pero no, en el sentido material del término, sus manifestaciones concretas (DUCROT, 1984, p. 208-209).

Pues bien, puede decirse, entonces, que de aquí se desprende la idea que postula la TPE acerca de que el sentido del enunciado -en la representación que este da de la enunciación- puede hacer aparecer voces que no son las de un locutor. En efecto, en palabras de García Negroni y Tordesillas (2001, p. 177), los enunciadores, al no ser personas, son puntos de perspectiva abstractos, los orígenes de los diferentes puntos de vista que se presentan en el enunciado. El locutor puede ser identificado con alguno o mantener cierta distancia respecto de ellos. Así, 
las diferentes relaciones que mantiene el $\mathrm{L}$ respecto de los E se darán en el análisis práctico, donde la configuración semántica del enunciado permitirá determinar qué posición ocupa el uno en relación con los demás.

A partir de lo expuesto en este apartado, podría decirse -en concordancia con García Negroni y Tordesillas (2001, p. 171)- que la originalidad de la TPE reside en que no solo da cuenta de las voces explícitas en el discurso (como lo hicieron los estudios sobre el discurso reproducido y las heterogeneidades enunciativas), sino también de las voces implícitas (voces virtuales) e incluso de los puntos de vista presentes en la enunciación, sin que estas figuras tengan que ver necesariamente con sujetos físicos. Asimismo, y dado que en el siguiente apartado se abordará la Teoría de la Argumentación en la lengua, elaborada paralelamente a la Teoría Polifónica de la Enunciación, vale aclarar desde ahora que referirse a una teoría lleva igualmente a referirse a la otra, dado que Ducrot decide situarse en aquel nivel de la lengua en que la argumentación y la enunciación se confunden. Al decir de García Negroni y Tordesillas (2001, p. 173), para Ducrot, argumentación y enunciación constituyen los ejes claves de su planeamiento científico y de la descripción semántica de los enunciados. El entramado de ambas facetas se refleja en la semántica argumentativa.

\section{La Teoría de la Argumentación en la Lengua}

Como ya ha sido adelantado en el apartado precedente (GARCÍA NEGRONI \& TORDESILLAS, 2001, p. 172-173), para Ducrot, argumentación y enunciación son indisociables, ya que constituyen la clave de la descripción semántica de los enunciados. En este sentido, la Teoría de la Argumentación en la Lengua (en adelante TAL), elaborada por Oswald Ducrot y Jean Claude Anscombre paralelamente a la TPE, se presenta como una teoría que intenta explicar la fuerza argumentativa de los enunciados; a la vez que sostiene, como hipótesis central, que el valor semántico profundo de las palabras es argumentativo, lo que los mismos autores resumen bajo el slogan: "La argumentación está en la lengua" (DUCROT, 1988, p. 65).

En efecto, caracterizada como antirrefencialista, antidescriptivista, antiveritativa y de inspiración estructuralista (GARCÍA NEGRONI, 2005, p. 12), la TAL postula que nuestras palabras tienen esencialmente un valor argumentativo, oponiéndose así a la concepción típica del descriptivismo, según la cual el sentido de los enunciados se calcula a partir de una significación que sería constante y de naturaleza vericondicional. Se propone, así, caracterizar las entidades de la lengua sin recurrir a un conocimiento previo de las propiedades del mundo o del pensamiento, es decir, sin recurrir a entidades extrañas a la lengua. En esta línea, postula que el enunciado no remite al mundo sino a otros discursos de los que ese enunciado es la continuación, o que puede serlo. Dicho de otro modo, para Anscombre y Ducrot (1983), el sentido de un enunciado debe describirse como una serie de instrucciones argumentativas que el mismo enunciado provee sobre su enunciación; es decir, el sentido se define como la evocación, en el discurso, de otros discursos o encadenamientos posibles. En este marco, la significación es caracterizada en términos de valor, por lo que la significación no es una constante, sino una función. Entonces, hablar no es describir o informar a propósito del mundo, sino dirigir el discurso en una cierta dirección, hacia ciertas conclusiones, alejándolo de otras. En una palabra, significar, para un enunciado, es orientar. La significación es, por lo tanto, de naturaleza instruccional. En síntesis, para la TAL, hablar es inscribir los enunciados en una cierta dinámica discursiva, la del texto total, que no es de naturaleza veritativa, sino argumentativa (ANSCOMBRE \& DUCROT, 1983; DUCROT, 1988; GARCÍA NEGRONI, 2005).

\subsection{Acerca de los Topoi}

Tal como lo plantea García Negroni (2005, p. 13), en un primer estadio ${ }^{4}$ de la TAL, la relación argumentativa es concebida como una relación binaria entre dos elementos discursivos, en la que el primero, llamado Argumento (A), es presentado por el locutor como destinado a hacer admitir el segundo, llamado Conclusión (C). Sin embargo, la relación binaria resulta insuficiente para explicar algunos encadenamientos argumentativos que no admiten interpretaciones "naturales". Por este motivo, a partir de 1986, Anscombre y Ducrot introducen un tercer término externo a la lengua, un principio general llamado "topos" 5 .

Así, según la Teoría de los Topoi (ANSCOMBRE \& DUCROT, 1986; ANSCOMBRE, 1995; DUCROT, 1988), estadio fundamental del desarrollo de la TAL, el topos remite a las creencias comunes de una comunidad lingüística; son principios argumentativos e ideológicos que no comportan ningún carácter lógico. Definidos

\footnotetext{
4 Vale aclarar que la TAL ha pasado por varios estadios en sus investigaciones; de la concepción binaria de los elementos argumentativos, en sus inicios, a la Teoría de los bloques semánticos (CAREL \& DUCROT, 2000-2005). En este trabajo se considera solo la versión estándar de la TAL (ANSCOMBRE \& DUCROT, 1986); es decir la que articula, en su formulación, a la Teoría de los Topoi. Esta elección no es arbitraria, sino que se fundamenta en la posibilidad de articular en el entramado argumentativo elementos extralingüísticos (i.e., presupuestos, ideologías) provenientes de la voz de la doxa que se representa a través de los Topoi.

5 El Topos es un concepto recuperado de la Retórica aristotélica. Para una mayor interiorización acerca del tema, consultar: Aristóteles. El arte de la retórica. Buenos Aires: Eudeba, 2010
} 
como el conjunto de "lugares comunes argumentativos" (DUCROT, 1988, p. 63), los topoi representan los trayectos que obligatoriamente deben tomarse con el fin de alcanzar, a través de un enunciado ocurrencia, una conclusión específica. Se trata, entonces, de discursos implícitamente utilizados, pero no asertados; es decir, el locutor no se presenta nunca como el autor de un determinado topos. En este marco, cabe aclarar que si bien los topoi no descansan sobre principios de orden lógico funcionan como los garantes de los encadenamientos argumentativos. En ese sentido podría decirse que, dentro de la dinámica discursiva, tienen un rol análogo a los axiomas de un sistema formal (GARCÍA NEGRONI, 2005).

Ahora bien, el topos presenta tres características principales: la universalidad, la generalidad, y la gradualidad (DUCROT, 1988, p. 71-73). La característica de universalidad es aplicada en un sentido restringido; es decir, sin relación con lo que los filósofos llaman universalidad. Remite, en cambio, a lo que una comunidad lingüística (compuesta al menos por el locutor y su alocutario) comparten. Por lo tanto, la universalidad es siempre supuesta, pretendida. Lo que cuenta es que el locutor presenta el topos sobre el que basa su argumentación como si fuera compartido por la comunidad lingüística de la que forma parte. En cuanto a la segunda característica, la generalidad, refiere a que el principio debe ser considerado válido (más allá de la situación a la que se lo aplica) para una multitud de situaciones análogas. De aquí se desprende que la generalidad deriva inmediatamente de la universalidad; es decir, si el principio debe ser admitido incluso antes de la aplicación que de él se haga, es necesario que valga para otras situaciones distintas de aquella a la que se aplica.

Respecto de la gradualidad, noción central de la teoría, puede decirse que los topoi, que aseguran el paso del enunciado a la conclusión, ponen en relación dos escalas graduales en una "correspondencia monótona". Esta metáfora matemática (DUCROT, 1988, p. 73) permite afirmar que cuando se recorre una de las escalas, se recorre también la otra; y que el sentido en que se recorre una implica un cierto sentido para el recorrido de la otra. Así, todo topos tiene presente dos predicados $P$ y $Q$ que los objetos pueden satisfacer según el más y el menos:

(...) una variación en la propiedad $P$ (crecimiento o disminución) trae aparejada, si todas las demás cosas permanecen iguales, una variación en la propiedad $Q$, siendo siempre la misma la correlación entre el sentido de variación de $P$ y el sentido de variación de $Q$ (DUCROT, 1988, p. 73).

A su vez, cada topos puede aparecer bajo dos formas tópicas (FT) conversas y equivalentes, puesto que no es posible admitir una sin admitir también la otra. Así, un topos $l$ (T1) comportará, al mismo tiempo, una FT'1 y una FT"1; es decir dos formas tópicas que expresarán dos aspectos recíprocos de la ideología vehiculizada por $\mathrm{T} 1^{6}$. Por último, cabe aclarar -en relación a la gradualidad tópica- que, concebida en estos términos, no debe comprenderse que cuanto más se sube en la escala $P$, más se sube en la escala $Q$, sino que cuanto más se sube en la escala $P$, más fuerte se hace el vínculo entre las dos escalas $P$ y $Q$ y más justificada se hace, entonces, la conclusión $Q$ (GARCÍA NEGRONI, 2005, p. 17).

Ahora bien, dado que los topoi son principios que no se apoyan en axiomas lógicos, $\mathrm{T} 1$ no es el único topos posible para garantizar un encadenamiento argumentativo. También puede considerarse T2, que es contrario a $\mathrm{T} 1 \mathrm{y}$ ambos representan ideologías diferentes. En otras palabras, dados dos "predicados tópicos" $P$ y $Q$, es posible construir dos topoi (T1 y T2) según que las dos gradaciones sean recorridas en el mismo sentido (T1) o en sentido inverso (T2). En el primer caso se dirá que la escala antecedente es un argumento para la escala consecuente; en el segundo, que es un argumento en contra de ella (GARCÍA NEGRONI, 2005, p. 15).

Finalmente, para dar cuenta de la vinculación ya mencionada (GARCÍA NEGRONI \& TORDESILLAS, 2001) entre la polifonía enunciativa y la argumentación, cabe señalar que en el marco de la TPE, Ducrot (1984) concibe el sentido y la significación como de una naturaleza diferente; se niega, como ocurría con las formulaciones más tradicionales, ${ }^{7}$ a considerar la significación como una parte del sentido. Es decir, el sentido nunca aparece como la suma de la significación más otras cosas, sino como una construcción que, habida cuenta de la situación del discurso, se opera a partir de las consignas especificadas en la significación. Al igual que para la TAL, aquí la significación remite a un conjunto de instrucciones para saber qué debe hacerse en presencia de un enunciado para interpretarlo; instrucciones que establecen las maniobras que se han de realizar para asociar un sentido a ese enunciado. Por lo que, para ambas teorías, la significación nunca es de naturaleza veritativa, sino instruccional.

Asimismo, en la formulación estándar de la TAL presentarse como si se discurriera sobre un estado de cosas significa convocar un principio argumentativo o topos, que no es otra cosa que las creencias y los presupuestos

\footnotetext{
6 Para una mayor interiorización acerca de las formas tópicas, ver Ducrot, Oswald. Argumentación y topoi argumentativos. Lenguaje en Contexto 1 , 1/2, p. 63-84; García Negroni, M. Marta. La Teoría de la Argumentación en la Lengua. De la Teoría de los Topoi a la Teoría de los Bloques Semánticos. In: SOMOLINOS, A. Rodríguez (coord.). Lingüística francesa (p.xx). Madrid: Liceus E-Excellence, 2005.

7 Refiere a la concepción habitual según la cual el sentido del enunciado incluiría, por un lado la significación de la frase, y por el otro, los añadidos aportados por la situación.
} 
compartidos por una comunidad lingüística; lo que desde la TPE de Ducrot se formula a través de la figura de los enunciadores o puntos de vista abstractos relativos a la situación comunicativa con los que el locutor puede o no identificarse (GARCÍA NEGRONI \& TORDESILLAS, 2001).

Ahora bien, como ya ha sido dicho, los topoi que vehiculizan los enunciados argumentativos no comportan un carácter lógico, sino ideológico, por lo que siempre es posible encontrar más de un topos conviviendo -muchas veces enfrentados- en una comunidad, en la representación de ideologías diferentes.

\section{La negación metadiscursiva y el uso del conector sino}

En el marco de la Teoría de la Polifonía Enunciativa, Ducrot (1984, p. 221) diferencia tres tipos de negaciones: la polémica, la descriptiva y la metalingüistica ${ }^{8}$ (de ahora en más, metadiscursiva ${ }^{9}$ ).

A partir de una descripción semántico-argumentativa (GARCÍA NEGRONI \& TORDESILLAS, 2001, p. 209), puede decirse que la negación metadiscursiva (NM) se caracteriza por descalificar el marco de discurso impuesto por una palabra anterior y por declarar, entonces, situarse siempre en un espacio discursivo diferente del rechazado o descalificado. En otras palabras, la NM se opone y contradice los términos mismos de un habla efectiva previa (o presentada como tal) a la que pretende refutar. En este sentido, no opone el punto de vista de dos enunciadores que un mismo locutor pone en escena, como lo haría la negación polémica (DUCROT, 1984, p. 221), sino dos locutores distintos o un mismo locutor (en tanto ex locutor), en momentos diferentes.

Dado que la NM es capaz de cancelar las presuposiciones del enunciado positivo subyacente, en

\footnotetext{
8 Dado que el análisis de los datos se efectuará en el marco de la negación metalingüística, no se describirán en esta oportunidad las otras dos negaciones mencionadas. Para una mayor interiorización acerca del tema, ver Ducrot, Oswald. El decir y lo dicho. Barcelona: Paidós, 1984.

9 Es importante aclarar que Ducrot no emplea el término metadiscursiva, sino metalingüística para referirse a las negaciones del tipo-no $p$, sino $q-$. Sin embargo, considerando las últimas formulaciones de García Negroni (2009-2013) al respecto, en las que reserva el término metalingüistica solo para la negación que rechaza algo del "código" (por alguna regla del léxico, de sintaxis, de registro, etc.) y utiliza el de "metadiscursiva" para referirse a la descalificación (y rechazo) de discursos ajenos previos (o presentados como tales en el propio discurso descalificador), se considera pertinente para este trabajo adoptar este último término para referirse a los enunciados que se analizan.

${ }^{10}$ El enunciado correctivo es optativo solo en el caso de la lectura "contrario a" (efecto contrastivo), dado que esta es considerada la interpretación básica de la NM, que declararía situarse en el espacio determinado por la escala antonímica. En los otros dos casos la rectificación es obligatoria, ya que es la que permite desencadenar una interpretación diferente de la básica al indicar cuál es el punto cuestionado (GARCÍA NEGRONI \& TORDESILLAS, 2001, p. 213).

11 Las negritas corresponden a la autora de este trabajo.
}

relación con los predicados escalares, no desencadenará jamás una lectura descendente. El efecto que producirá, en cambio, podrá ser contrastivo, ascendente, o distinto. Por esta razón, puede afirmarse que su función principal es la de instaurar un nuevo espacio de discurso: el antonímico, el extremo, o simplemente, otro diferente (GARCÍA NEGRONI, 1998, p. 250).

Por otra parte, la NM, puede aparecer seguida por un enunciado correctivo, el que introduce la rectificación del marco o topos rechazado ${ }^{10}$. En este sentido, el conector sino, siempre prolongación de una negación metadiscursiva, introduce el punto de vista correspondiente a la rectificación de una aserción rechazada, sea esta real o virtual, o aun cuando la refutación se sitúe en un marco ficticio desplegado por el discurso (ANSCOMBRE \& DUCROT, 1997, p. 27).

\section{Análisis de los enunciados}

Lo que sigue, es el análisis de los enunciados estructurados en base a la NM, emitidos por la persona entrevistada (de ahora en adelante M) para el que se seleccionaron seis enunciados del tipo -no p $S N q$-:

1. "(...) una de las condiciones, cuando nosotros asignamos la casa es que quede claro que ellos también tienen que colaborar con la construcción de su casa y no ${ }^{11}$ es que nosotros vamos a construir su casa, sino que vamos a construir su casa con ellos".

2. "La idea no es llegar nosotros e imponer no sé, ni microcréditos, ni capacitación de oficios, ni ningún plan, sino esperar a que las familias mismas digan cuáles son sus necesidades".

3. “(...) no nosotros hacer el trabajo por ellos, sino brindarles las herramientas y las redes para que ellos mismos puedan autogestionar sus soluciones".

4. "Nuestra idea no es construir la casa e irnos, sino que después seguimos yendo a los barrios, seguimos visitando las familias".

5. "(...) nosotros lo que tratamos de medir siempre es no solo si pagan, sino si está la voluntad (...)".

6. “(...) no es una cuestión de plata, sino de ver si la familia realmente se interesa o no".

Para el análisis de los enunciados se consideraron las siguientes categorías:

a) Marco discursivo o topos rechazado; b) Relación con los predicados escalares y los efectos que consecuentemente produce (i.e., lectura "contrario a", lectura "más que", lectura "diferente de"); c) Locutor adverso (real o virtual) que emitiera el enunciado positivo subyacente; d) Marco discursivo o topos aceptado que instaura la rectificación. 
Con el fin de contextualizar el análisis de los enunciados precedentes, se transcribe a continuación un fragmento de la entrevista a M:

Sabemos que, como estamos trabajando con los más pobres entre los pobres, es difícil que puedan juntar toda la plata de una. Por otro lado, el tema de que paguen el $10 \%$ responde a la filosofía esta de no ser asistencialistas y tratar de que la familia haga un esfuerzo para conseguir su casa: que la sientan como propia y no como un regalo, y también bueno, para cultivar lo que es eso de la cultura del esfuerzo, del trabajo.

A partir de lo expuesto por $\mathrm{M}$, podría pensarse que T1 estaría representado por el "asistencialismo", que predicaría: "Las personas que se encuentran en situación de pobreza (i.e., carentes de recursos), requieren asistencia". Si se plantearan las escalas graduales, dentro de T1, se encontrarían dos escalas: la de la pobreza y la de la asistencia. Si además, estas se recorrieran en el mismo sentido, sería imaginable un predicado tópico $\mathrm{p} 1$ : "Son pobres", que conectara argumentativamente a través de $\mathrm{T}^{12}$ con la conclusión q1: "Necesitan asistencia. Nosotros podríamos construirles una casa". Entonces, dentro de este marco discursivo, estaría justificado que esta ONG, el Estado, o quien fuere, le construyera una casa gratuitamente para asistirlos ${ }^{13}$. Sin embargo, si se toman como ejemplos 1 y 3 , es justamente esta la aserción p' rechazada $\mathrm{y}$, consecuentemente, refutado $\mathrm{T} 1$ : el "asistencialismo".

En 1: - “(...) no es que nosotros vamos a construir su casa, (...)"

En 3: - “(...) no nosotros hacer el trabajo por ellos, (...)”

Si se consideran ahora los enunciados correctivos correspondientes, se imponen al menos dos preguntas: ¿cuál es la lectura que, en relación con los predicados escalares, introduce el conector sino? y ¿cuál es el marco discursivo o topos aceptado que introduce la rectificación?

En 1: - "(...) sino que vamos a construir su casa con ellos."

En 3: - “(...) sino brindarles las herramientas y las redes para que ellos mismos puedan autogestionar sus soluciones."

Pareciera que el topos convocado por la rectificación (T2), estaría representado por "la cultura del esfuerzo". En este caso, podría pensarse que T2 predicaría: "Es meritorio ganarse las cosas con esfuerzo", o "El esfuerzo merece ser recompensado". En este sentido, se podrían construir dos escalas graduales: la del esfuerzo y la del mérito. Si además se recorrieran las escalas en el mismo sentido, podría imaginarse un predicado tópico p2: "Se han esforzado", que conectara argumentativamente, a través de T2 ${ }^{14}$ con la conclusión q2:"Merecen alguna recompensa. Podríamos colaborar en la construcción de su casa". Entonces, el marco discursivo que introduce la rectificación, tanto en 1 como en 3 , justifica brindar herramientas o colaboración solo como recompensa al esfuerzo realizado que, por otra parte, parecería estar emparentado directamente con el pago de la casa ${ }^{15}$. Por lo tanto queda descalificado T1: "el asistencialismo". Ahora bien, dado que T1:"el asistencialismo" y T2:"la cultura del esfuerzo" no son contrarios (i.e., que una familia carente de recursos requiera de "asistencia" no excluiría directamente el "esfuerzo" por subsistir), el efecto que desencadenaría el conector sino no sería la lectura antonímica, sino una diferente. Sin embargo, en este contexto, en el que el "asistencialismo" y el "esfuerzo" quedan asociados con la gratuidad o el pago de la casa respectivamente (y arriesgando un poco más, con la pasividad y el trabajo) ${ }^{16}$, el efecto que desencadena $S N$ es la lectura antonímica.

Si se toman ahora los enunciados 5 y 6 , podrá notarse que $\mathrm{M}$ se refuta a sí mismo (en tanto ex-locutor) en relación a lo dicho en 1 y 3 . Allí, el locutor introducía como marco discursivo adecuado "la cultura del esfuerzo", que como ya se planteó, está emparentado con el pago de la casa. Sin embargo, en 5 y en 6 realiza un nuevo movimiento discursivo: refuta el marco que es presentado por él mismo como adecuado en 1 y en 3 :

En 5: - “(...) nosotros lo que tratamos de medir siempre es no solo si pagan, (...)"

En 6: - “(...) no es una cuestión de plata, (...)”

Ahora bien, dado que la negación metadiscursiva es ambigua hasta el momento de la aparición del enunciado correctivo (GARCÍA NEGRONI, 1998; (GARCÍA NEGRONI \& TORDESILLAS, 2001), es necesario acudir a ellos para entender cuál es el punto cuestionado:

En 5: - “(...) sino si está la voluntad (...)"

En 6: - “(...) sino de ver si la familia realmente se interesa o no"

\footnotetext{
12 En este caso, bajo la FT"1 (GARCÍA NEGRONI, 2005): "Cuanto más pobre, más asistencia necesita".

13 Por otra parte, dentro de la escala de la pobreza, habría que situarse en el grado extremo, dado que son los "más pobres entre los pobres" (fragmento de la entrevista a M), lo que justificaría aún más regalar una casa de madera prefabricada para asistirlos.

${ }^{14}$ Bajo la FT'2 (GARCÍA NEGRONI, 2005): "Cuanto más esfuerzo se realice, más meritorio es".

${ }^{15}$ Fragmento citado de entrevista a M

${ }^{16}$ Idem nota 15
} 
Pareciera que el topos adecuado para garantizar los encadenamientos argumentativos en 1 y en 3 es ahora refutado por considerarlo insuficiente para justificar la colaboración de la ONG. Podría pensarse, entonces, que T2 (el topos adecuado que introduce la rectificación), tanto en 5 como en 6 , es ahora el del "compromiso", que predicaría: "Comprometerse con lo que se hace (i.e., manifestar voluntad e interés, entre otras cosas) es esencial para obtener buenos resultados". En relación con los predicados escalares podría leerse entonces: "Cuanto mayor es el compromiso (i.e., voluntad, interés, etc), mejores resultados se obtienen". En este caso, como T1: "cultura del esfuerzo" y T2: "compromiso" no son contrarios, el conector sino introduce la lectura "diferente $d e " .{ }^{17}$

Ahora, si bien en 5 y 6 el locutor refutado es él mismo (en tanto ex-locutor), no ocurre lo mismo en 1-4, en los que el enunciado positivo subyacente refutado parece haber sido emitido por un locutor adverso, el que se sitúa en el marco del asistencialismo. Dice M:

(...) las políticas sociales (...) suelen ser muy asistencialistas y muy como a corto plazo. (...) sabiendo igual que hay problemas concretos de madres que por ahí no tienen para comer y que necesitan los planes Jefes y Jefas, o la bolsa de comida o el Plan Vida para poder subsistir porque es lo único que tienen. Yo eso lo entiendo, pero me parece que sí hay que buscar también que la familia haga un esfuerzo, y tratar de sacar a la familia de esa relación que tienen hoy con el Estado que es como que nos quedamos esperando a que nos traigan la bolsa de comida o a recibir el plan $(\ldots)$

Si se retoma el análisis de 1 y 3 , podría pensarse que el locutor adverso L1 es el Estado (como locutor virtual), que implementa las políticas sociales asistencialistas, y del que "todo se espera." L2 lo refuta (como ya se ha planteado), proponiendo como marco adecuado la "cultura del esfuerzo" y, por lo visto, en 5 y 6 sube la apuesta refutándose a sí mismo, y proponiendo además "el compromiso." Si se toman ahora como ejemplos 2 y 4 , se podrá observar que $\mathrm{M}$ refuta nuevamente el marco del asistencialismo y, consecuentemente a L1 que, como ya se dijo, sería el Estado:

En 2: - "La idea no es llegar nosotros e imponer no sé, ni microcréditos, ni capacitación de oficios, ni ningún plan, (...)" Luego introduce en la rectificación

\footnotetext{
${ }^{17}$ Pareciera que el compromiso es más abarcativo que el esfuerzo, es decir, el esfuerzo "no es suficiente". Pero como esfuerzo y compromiso no están en la misma escala argumentativa, $S N$ no desencadena aquí la lectura "más que", sino la lectura "diferente de" (i.e., remite a otra escala).
}

nuevamente el marco del "compromiso": - “(..), sino esperar a que las familias mismas digan cuáles son sus necesidades".

En 4: - "Nuestra idea no es construir la casa e irnos, (...)", vuelve a refutar a L1, el Estado, que desde el "asistencialismo" implementaría "políticas a corto plazo" e introduce la rectificación: - "(...), sino que después seguimos yendo a los barrios, seguimos visitando las familias".

Ahora bien, pareciera que el compromiso planteado como condición para que una familia sea "beneficiada", alcanza también a los integrantes de la ONG. Así, luego de la refutación de L1 y su correspondiente marco discursivo, la rectificación que introduce L2, en 4, sitúa nuevamente el marco aceptado en el "compromiso", esta vez por parte de los integrantes de la ONG. También, en los casos 2 y 4 , la lectura que desencadena $S N$ es "diferente de".

\section{Consideraciones finales}

Si se retoma la pregunta formulada en el inicio teniendo en cuenta el análisis de los enunciados, podría desplegarse ahora de la siguiente manera: ¿por qué $\mathrm{M}$ utiliza sistemáticamente la NM para relatar el modo de trabajo o las actividades que realiza esta $\mathrm{ONG}$, en lugar de estructurar su discurso a partir de enunciados declarativos? Considerando las ideas previas ya explicitadas y tomando como apoyatura algunos aportes de la Teoría Psicoanalítica, se intentará en lo que sigue presentar algunas conclusiones (por demás provisionales) del análisis realizado.

Freud (1925, p. 253) plantea que un contenido representacional o de pensamiento reprimido puede irrumpir en la conciencia a condición de que se deje negar. La negación es un modo de tomar noticia de lo reprimido o, mejor dicho, es ya una cancelación de la represión, lo que no implica una aceptación de lo reprimido; la función intelectual se separa aquí del proceso afectivo. El juicio adverso es, por lo tanto, el sustituto intelectual de la represión; su "no" es una marca de ella, su certificado de origen.

Ahora bien, el modo en que un sujeto estructura su discurso no responde a la casualidad, sino a una cierta causalidad psíquica que, la mayoría de las veces, el "yo" desconoce. En este sentido, la "elección" de M de presentar su relato de lo que esta ONG realiza en base a la NM podría responder a una estrategia discursiva de oposición respecto de aquello de lo que el "yo" se quiere diferenciar. En otras palabras, podría pensarse que $\mathrm{M}$ introduce el "no" -y su consecuente refutación del marco del "asistencialismo"- para aceptar en la conciencia (vía la negación) aquello con lo que, a nivel inconsciente, se 
identifica. De esta manera, el reconocimiento -por parte del yo- de lo inconsciente se expresa en una fórmula negativa quedando, en relación a los pensamientos reprimidos, en un lugar de desconocimiento.

Por su parte, Lacan (1953 ) plantea que el término alemán Verneinung no debe ser entendido como negación en el sentido lógico o gramatical del término, sino como denegación, no tanto en el sentido de denegar -no conceder lo que se pide o solicita-, como en el sentido de "rechazar" una afirmación que "he enunciado o se me atribuye". Teniendo en cuenta esta conceptualización podría pensarse que $\mathrm{M}$ atribuye al "Estado" -como locutor adverso- el enunciado subyacente, rechazado en el plano consciente, nuevamente como una marca de lo que ha sido afirmado en el inconsciente.

A partir de lo dicho, ¿cómo justificar que $\mathrm{M}$ se identifica justamente con aquello que rechaza?; ¿cómo podría traducirse desde el psicoanálisis esta suposición?

En 1936, Lacan presenta el artificio del espejo para dar cuenta del papel del otro, del semejante, en la constitución del yo. Es decir, conceptualiza la formación yoica a partir de un acto psíquico mediante el cual el yo se constituye como "otro". Este acto psíquico es la identificación (i.e., la trasformación producida en el sujeto cuando asume una imagen). Ahora bien, esa imagen que por un lado lo representa, y a su vez es otro, va a simbolizar la permanencia del yo como imagen, pero a la vez, va a prefigurar el destino alienado y alienante enajenador del yo. Este desarrollo inaugura para el sujeto, presa de la ilusión por la identificación con la imago del semejante, el drama de una dialéctica que desde entonces liga al yo con situaciones socialmente elaboradas (LACAN, 1936, p. 88).

En el plano imaginario, no hay lugar para dos, la frase "yo es otro" debe tomarse, entonces, literalmente. En lo imaginario no existe la terceridad, sino una dualidad especular rivalizante para la que no hay salida. Es el registro de la agresividad, es "yo" o es "otro". Es necesario introducir algo del orden simbólico, algo del orden de la palabra, para que se constituya la dimensión subjetiva. El registro simbólico que se plantea en relación al gran Otro del lenguaje constituye la alteridad radical que inaugura una nueva escena. Es decir, la dimensión de la palabra apacigua y regula la relación alienante imaginaria.

Finalmente, podría concluirse que la "elección" por parte de $\mathrm{M}$ de la NM, como estrategia discursiva, responde al intento de diferenciación de ese "otro", representado por el Estado como locutor "virtual"18. En otras palabras, el uso del "no" como marca de la represión (función simbólica por excelencia) es el mecanismo psíquico empleado por M para salir del drama de la especularidad y situarse, de esta manera, en otra escena.

\section{Referencias}

ANSCOMBRE, Jean-Claude; DUCROT, Oswald. Deux mais en française? Lingua, v. 43, p. 23-40, 1977.

DUCROT, Oswald. El decir y lo dicho. Buenos Aires: Paidós, 1984.

DUCROT, Oswald. Argumentación y topoi argumentativos. In: Lenguaje en contexto 1, 1/2, p. 63-84, 1988.

FREUD, Sigmund. La Negación. In: FREUD, Sigmund. Obras completas. Buenos Aires: Amorrortu, 1992. Tomo XIX, p. 249-257.

GARCÍA NEGRONI, M. Marta. La Teoría de la Argumentación en la Lengua. De la Teoría de los Topoi a la Teoría de los Bloques Semánticos. In: SOMOLINOS, A. Rodríguez (coord.). Lingüística francesa. Madrid: Liceus E-Excellence, 2005. (p. Xx).

GARCÍA NEGRONI, M. Marta. La negación metalinguística, argumentación y escalaridad. Signo y Seña, Revista del Instituto de Lingüística, Consejo Nacional de Investigaciones Científicas y Técnicas Universidad de Buenos Aires, n. 9, 1998.

GARCÍA NEGRONI, M. Marta; TORDESILLAS, Marta. La enunciación en la lengua. De la deixis a la polifonía. Madrid: Gredos, 2001.

KOVACCI, Ofelia. Las construcciones con sino y no... pero, y los campos léxicos. In: Estudios de Gramática española. Buenos Aires: Hachette, 1986. p. XXX.

LACAN, Jacques. El estadio del espejo como formador del yo (je) tal como se nos revela en la experiencia psicoanalítica. In: Escritos 1. Buenos Aires: Siglo veintiuno editores, 1988.(p. 86-93).

LACAN, Jacques. Introducción y respuesta a una exposición de Jean Hyppolite sobre la Verneinung de Freud. In: El Seminario, Libro 1: Los escritos Técnicos de Freud. Buenos Aires: Paidós, 1992a. p. XXX.

LACAN, Jacques. La tópica de lo imaginario. In: El Seminario, Libro 1: Los escritos Técnicos de Freud. Buenos Aires: Paidós, 1992b. p. XXX.

Recebido: 15 de outubro de 2015.

Aprovado: 20 de novembro de 2015.

Contato:marcelascazes@gmail.com

$\overline{18}$ Tomado aquí en el sentido "especular" del término. 